\title{
Factors of Providing the Continuity of Teaching Mathematics During Transition from High School to University
}

\author{
Yuliia Botuzova \\ Department of Math, Volodymyr Vynnychenko Central Ukrainian State Pedagogical University, Ukraine
}

Received November 24, 2019; Revised January 22, 2020; Accepted February 18, 2020

Copyright $\odot 2020$ by authors, all rights reserved. Authors agree that this article remains permanently open access under the terms of the Creative Commons Attribution License 4.0 International License

\begin{abstract}
The article deals with a current problem of providing the continuity of teaching mathematics during students' transition from high school to university. Today, there are a lot of scientific researches dealing with the continuity of education, which show the interest of scientists to this topic. Therefore, available researches were analyzed, summarized and systemized. The conclusion from this analyzation is that in most studies, scientists distinguish pedagogical, didactic, methodical, organizational conditions for providing continuity in the educational process. In our research, all these conditions were grouped into 6 blocks: content-related, organizational, methodical, instrumental, evaluative, social-psychological. According to the blocks, a questionnaire was developed. It contained 42 questions. The answer to each question implied that the respondent made a judgment on a scale of 1 to 5 points. Students of 1-3 courses of the Physics and Mathematics Faculty of the pedagogical university participated in the survey. The empirical data obtained were processed using the IBM SPSS Statistics 20, computer statistical package. A factor analysis method was chosen to analyze the data, because it reduces the large number of variables to fewer independent influential values - factors. The article describes in detail the algorithm for working with data. The results of the factor analysis were interpreted. The conducted research allowed us to define four factors that influence the process of providing the continuity of mathematics teaching.
\end{abstract}

Keywords The Continuity of Teaching Mathematics, Teaching Process, Factor Analysis

\section{Introduction}

The main condition of the national education system functioning is providing the structural, organizational, purposeful and informative interconnections of all its levels. The most important is the existence of these connections at the transition stages of students from one level of education to another, as there is a change in the learning environment, curriculum and approaches to teaching subjects. These changes are inseparably connected with the notion of continuity, which is the subject of philosophy, sociology, pedagogy, didactics and methodology study.

In the process of active reformation of education in Ukraine, issues of providing continuity of education become more important and require a variety of pedagogical studies. According to studies of A. Batarshev[2], P. Mikhailov[13], A. Smantser[19], continuity is a didactic principle, aimed at maintaining the continuity of the educational process by means of providing links within and between levels of education. Such definition of continuity was a basic of the study, with that the methodological features of teaching mathematics were taken into account.

Today there are a lot of scientific researches dealing with the continuity of education, which show the interest of scientists to this topic. We decided to focus on the peculiarities of providing the continuity of mathematics teaching process during the transition of students from high school to university, in particular pedagogical one.

\section{Materials and Methods}

The first stage of this study was a detailed theoretical analysis of the scientific literature in the problem of continuity in education. After systematization and generalization of studied materials, it turned out that in most studies, scientists distinguish pedagogical, didactic, methodical, organizational, psychological conditions for ensuring continuity in the educational process and in mathematics in particular. 
Pedagogical conditions - a set of external factors and circumstances that influence the course of learning activities. This is a common concept. As it found out, the conditions derived from the "pedagogical conditions" (organizational, didactic, methodical, psychological-pedagogical, social-psychological, social-pedagogical, etc.) also uses in the practical scientific researches in the field of pedagogy and education. They clarify the scope of scientific and pedagogical search, as well as the areas of research related to various aspects of improving educational systems.

Each scientist considers the continuity of teaching in one or more perspectives, not taking into account all its versatility. Therefore, the purpose of this study is to point out the factors of influence on the process of providing the continuity of teaching mathematics in "School-Pedagogical University" system.

\subsection{Literature Overview}

The focus in the analysis of scientific literature appealed to those studies, which set out the conditions for the implementation of continuity in the educational process, in particular the teaching of mathematics.

B. Ananiev[1] noted that in pedagogical science the problem of continuity arises when drawing up and reviewing educational standards for related levels of education, as well as when solving the main problems of educational content. In solving these problems, it is necessary to guarantee the formation of a knowledge system in each individual subject by years of study, to take into account the diversity of teaching methods and guidance of students' independent work.

A. Pyshkalo[18], according to his own methodological approach, identifies the internal and external manifestations of the continuity problem in the methodical system of teaching each individual subject, in particular, the purposes, content, methods, tools and organizational forms of teaching.

Linear-concentric structure of a school mathematics course allows to distinguish two directions of providing continuity in teaching a subject:

1) continuity between related levels of teaching;

2) continuity within each level of the course: a) continuity within each course of mathematical disciplines (arithmetic, algebra, algebra and the elements of analysis, geometry); b) continuity between courses in mathematical subjects, in particular, between propaedeutic and systematic courses (eg, algebra and geometry, arithmetic and algebra, arithmetic and geometry, etc.).

A group of researchers (K. Mishareva, V. Rudenko, A. Shepetov, etc.[14]) identifies approaches to the implementation of continuity between propaedeutic and systematic courses: the presence of a unifying vision in related courses; the development of thinking methods that are of particular importance in mathematics (induction and deduction, analysis and synthesis, generalization and abstraction), the gradual increase of deductive reasoning level and abstraction and in the development of concepts at the next stages of teaching; organization of revising work, which provides the consolidation and development of skills necessary for successful mastering of the following material; independent thinking training; matching the difficulty levels of the tasks between related courses.

E. Komarova[11] notes that the problem of continuity in teaching mathematics is formally solved through textbooks and manuals, normative documents, as well as through the communication of teachers working at related levels of education. Were offered the following ways and means of providing continuity: creating a system of repetition that includes updating, generalizing and organizing students' knowledge; conducting general lessons in temporary groups of different age students; using of generalized algorithms and techniques of mathematical activity; widespread use of symbolic visuals.

O. Stonda[20] considers the necessity of identifying the following didactic conditions: didactic preparation of Pedagogical University teachers to form the students' readiness to ensure continuity in learning in their future professional activity; introduction of elective courses in the educational process of pedagogical universities with the aim of more effective didactic preparation for providing continuity in teaching students.

K. Gnezdilova [7] identifies the following basic prerequisites for effective preparation of mathematics teachers for providing continuity in teaching: awareness of the problem of continuity by future teachers; understanding of the specifics of educational activities in secondary schools and universities; acquaintance with the ways of interaction of secondary schools and universities; mastering methods of pedagogical diagnostics to identify students' abilities and to analyze their educational achievements and so on.

M. Didovik[6], on the basis of the continuity model, formulates and substantiates the pedagogical conditions for the implementation of the continuity of physic-mathematical preparation of pupils and students in the system of stage education "Lyceum-High School": the content consistency of educational material in physics and mathematics at different stages of teaching; rational choice and coherence of forms, methods, didactic techniques and means of physical and mathematical preparation in the educational system "Lyceum-High School"; coordination of pedagogical activity of physic-mathematical disciplines teachers and other teachers in the educational system "Lyceum-High School"; motivation formation of educational and professionally directed activity of pupils and students at all stages of studying.

M. Bosovsky[3] notes that the implementation of continuity between the school and university course of mathematics can be carried out in two directions. The first one is related to basing of the new content on the already learned content in the previous stage of education, and then 
there is connection between the material studied at the university and the one taught at school. The second direction is when the content at this stage of education prepares students for successful mastering of the material in the subsequent stages, i.e. there is a connection between the material studied at school and the material that is to be learned at university. And then continuity functions become close to those of the propaedeutic.

At the same time, it is important to consider the continuity in the student's personality formation, because the procedural and substantive aspects of teaching are built taking into account the logic of educational and cognitive activity, age and psychological and physiological features of students. Therefore, supporting university systems are important here, because they can enable socialization and adaptation of students.

Positive relationships may be established by student guides at induction, student peer coaches (Carter and McNeill[5]), staff as course co-ordinators working with small groups of first-year students (Huon and Sankez[8]) and improved student/staff ratios in first-year classes (Peel[16], Pascarella and Terenzini[15]). Westlake[21] offers using the most student-focused members of staff for first-year students wherever possible. Pitkethly and Prosser[17] write about importance of using: systems of information-giving, including orientation tours; student handbooks; course outlines with clear statements of aims, objectives and assessment methods; careers information integrated into courses.

Keup and Barefoot[9] indicate how student participation in seminars and workshops can sustain this socialization process during the first year. The findings of York and Thomas[22] suggest that universities must be prepared to respond positively on an institution-wide basis, to maximize the success of all their students. They identify the following potential success factors: an institutional climate supportive in various ways of students' development, that is perceived as "friendly"; an emphasis on support leading up to, and during, the critically important first-year of study; an emphasis on formative assessment in the early phase of programs; a recognition of the importance of the social dimension in learning activities; recognition that the pattern of students' engagement in higher education is changing, and a preparedness to respond positively to this in various ways.

\subsection{Data Collection and Results}

The next stage of this study was to summarize, systematize of all the above mentioned conditions. They were grouped into 6 blocks: content-related, organizational, methodical, instrumental, evaluative, social-psychological. A questionnaire was also developed that contained 42 questions, divided into the 6 blocks mentioned above. The answer to each question implied that the respondent made a judgment on a scale of 1 to 5 points.

This study is a descriptive research carried out at the
Volodymyr Vynnychenko Central Ukrainian State Pedagogical University in Kropyvnytskyi, Ukraine. 4519 students enrolled in this university at the beginning of 2019. At this time, the total number of students at the Physics and Mathematics Faculty of this university was 604. Total coverage sample includes 126 students of 1-3 course of this faculty. Students were randomly selected. The level of experience in mathematics was also important for this study, so approximately the same number of students was selected according to the years of study at the university: 40 first-year students, 48 second-year and 38 third-year students. The fourth-year students (final year of study at the bachelor's level) did not participate in the study, because they have completed the fundamental mathematical training in the third year. In the final year of studying, they more focus on the methods of teaching math.

The questionnaire was offered to the selected students. The respondents answered the questions on their own, in a relaxed atmosphere, without missing a single question.

The empirical data obtained were processed using the IBM SPSS Statistics 20, computer statistical package.

A factor analysis method was chosen to analyze the data, because it reduces the large number of variables relevant to the available observations to fewer independent influential values - factors. It should be noted that the variables highly correlated with each other unit in one factor. The purpose of factor analysis is to find such complex factors that most fully explain the connections observed between the available variables [4].

Factor analysis is based on the calculation of the correlation coefficients between the variables, and therefore the data set must meet certain requirements.

1. The data set must be represented as a two-dimensional matrix.

2. Analyzed variables should be entered in the columns of the matrix and the values of those variables should be entered in rows.

3. There should be no spaces in the matrix.

4. It is desirable that the number of rows (respondents) is greater than the number of columns approximately three times.

5. The number of variables (columns) should be more enough (more than 10) [10].

The number of variables in the study is equal to the number of questions in the questionnaire and is 42 . All these variables are ordinal and their values represent categories with some inherent in them ordering: importance level, difficulty level of a problem, degree of satisfaction, etc.

To calculate the statistical characteristics and the survey parameters dependence, a common survey matrix was constructed, where 42 questions are columns and rows represent the values of the survey parameters obtained from the respective observations (respondents' answers 126 people, three times the number of variables). Therefore, the input data for the IBM SPSS Statistics 20 program is a 
126x42 matrix.

Table 1. Measure of Sampling Adequacy and the Bartlett's Criteria

\begin{tabular}{|c|c|c|}
\hline Kaiser-Meyer-Olkin Measure of Sampling Adequacy & 0.762 \\
\hline \multirow{3}{*}{$\begin{array}{c}\text { Bartlett's Test of } \\
\text { Sphericity }\end{array}$} & $\begin{array}{c}\text { Approximation } \\
\text { Chi-squared }\end{array}$ & 18213.63 \\
\cline { 2 - 3 } & Degrees of freedom & 861 \\
\cline { 2 - 3 } & Significance & 0.00 \\
\hline
\end{tabular}

Kaiser-Meyer-Olkin Measure of Sampling Adequacy and the Bartlett's Test of Sphericity were used for testing the feasibility of factor analysis. According to the results of conducted observation, the criteria values are presented in Table 1.
The Measure of Sampling Adequacy of the KMO according to the results of the observation assumes a value of 0.762 , which allows carrying out further calculations with acceptable level of the results accuracy. In addition, the Bartlett Sphericity criterion with a high accuracy of $p$ $<0.00$ refutes the hypothesis of the uniqueness of the correlation matrix and allows the usage of available observational data for factor analysis.

In the language of factor analysis, the proportion of variance of a single variable belonging to a common factor (and collective with other variables) is called communality. Table 2 presents the communalities: the names of all 42 variables and the separated values.

Table 2. Communalities

\begin{tabular}{|c|c|}
\hline Variables & Extraction \\
\hline Difficulties of understanding mathematics at university & 0.805 \\
\hline Difficulties of studying the theorems proofs & 0.751 \\
\hline The complexity of mathematical symbols & 0.608 \\
\hline Level of basic school mathematics knowledge & 0.800 \\
\hline Connection between school and university mathematics courses & 0.805 \\
\hline Content details of the university mathematics course & 0.660 \\
\hline The desire to get mathematical and professional competences & 0.784 \\
\hline The importance of test forms of control at university & 0.430 \\
\hline The importance of using distance learning technologies & 0.443 \\
\hline Difficulty in taking colloquiums in mathematics & 0.764 \\
\hline Difficulties in understanding lectures as a form of teaching process & 0.469 \\
\hline Difficulties in understanding seminars as a form of teaching process & 0.446 \\
\hline The importance of laboratory work using ICT & 0.483 \\
\hline The complexity of individual tasks & 0.725 \\
\hline Interest in participating in subject competitions & 0.686 \\
\hline The importance of problematic teaching methods & 0.613 \\
\hline The importance of interactive teaching methods & 0.637 \\
\hline The importance of revising a school math course with a university teacher & 0.656 \\
\hline The importance of interesting intensive accessible teaching of mathematics & 0.660 \\
\hline Affordable understanding of mathematics teaching at university & 0.533 \\
\hline Affordable understanding of mathematics at school & 0.572 \\
\hline The importance of applying knowledge to life situations & 0.715 \\
\hline The importance of content integration, interdisciplinary interconnection & 0.700 \\
\hline The importance of level differentiation, individual approach & 0.573 \\
\hline Availability of information sources for independent work & 0.542 \\
\hline The importance of visual presentation of educational material & 0.545 \\
\hline The importance of using ICT as visual aids & 0.509 \\
\hline The importance of having quality teaching materials & 0.653 \\
\hline The importance of having a distance course integrated into the discipline & 0.587 \\
\hline The importance of using mathematical software & 0.493 \\
\hline The importance of using smartphones in teaching & 0.552 \\
\hline The importance and convenience of a 12 point scoring system & 0.505 \\
\hline The importance of a unified assessment system at school and university & 0.690 \\
\hline
\end{tabular}




\begin{tabular}{|l|l|}
\hline The importance of understanding different assessment systems & 0.696 \\
\hline The importance of being able to translate points from one scale to another & 0.748 \\
\hline The level of self-organization in the educational process & 0.784 \\
\hline The importance of a mathematics teacher's personal example & 0.501 \\
\hline The importance of an academic group curator support & 0.369 \\
\hline Wish to carry out pedagogical activity & 0.774 \\
\hline The difference between school and university & 0.322 \\
\hline The fear of making a mistake & 0.401 \\
\hline The importance of participating in community activities & 0.168 \\
\hline
\end{tabular}

Table 3. Total Variance Explained

\begin{tabular}{|c|c|c|c|c|c|c|c|c|c|}
\hline \multirow{2}{*}{ Component } & \multicolumn{4}{|c|}{ Initial Eigenvalues } & \multicolumn{3}{c|}{ Extraction Sums of Squared Loadings } & \multicolumn{3}{|c|}{ Rotation Sums of Squared Loadings } \\
\cline { 2 - 11 } & Total & $\begin{array}{c}\text { \% of } \\
\text { variance }\end{array}$ & Cumulative \% & Total & $\begin{array}{c}\text { \% of } \\
\text { variance }\end{array}$ & Cumulative \% & Total & $\begin{array}{c}\text { \% of } \\
\text { variance }\end{array}$ & Cumulative \% \\
\hline 1 & 13.539 & 32.237 & 32.237 & 13.539 & 32.237 & 32.237 & 10.633 & 25.316 & 25.316 \\
\hline 2 & 7.193 & 17.127 & 49.364 & 7.193 & 17.127 & 49.364 & 6.039 & 14.378 & 39.694 \\
\hline 3 & 2.438 & 5.804 & 55.168 & 2.438 & 5.804 & 55.168 & 5.813 & 13.841 & 53.535 \\
\hline 4 & 1.988 & 4.734 & 59.902 & 1.988 & 4.734 & 59.902 & 2.674 & 6.368 & 59.902 \\
\hline 5 & 1.665 & 3.965 & 63.867 & & & & & & \\
\hline 6 & 1.452 & 3.457 & 67.324 & & & & & & \\
\hline
\end{tabular}

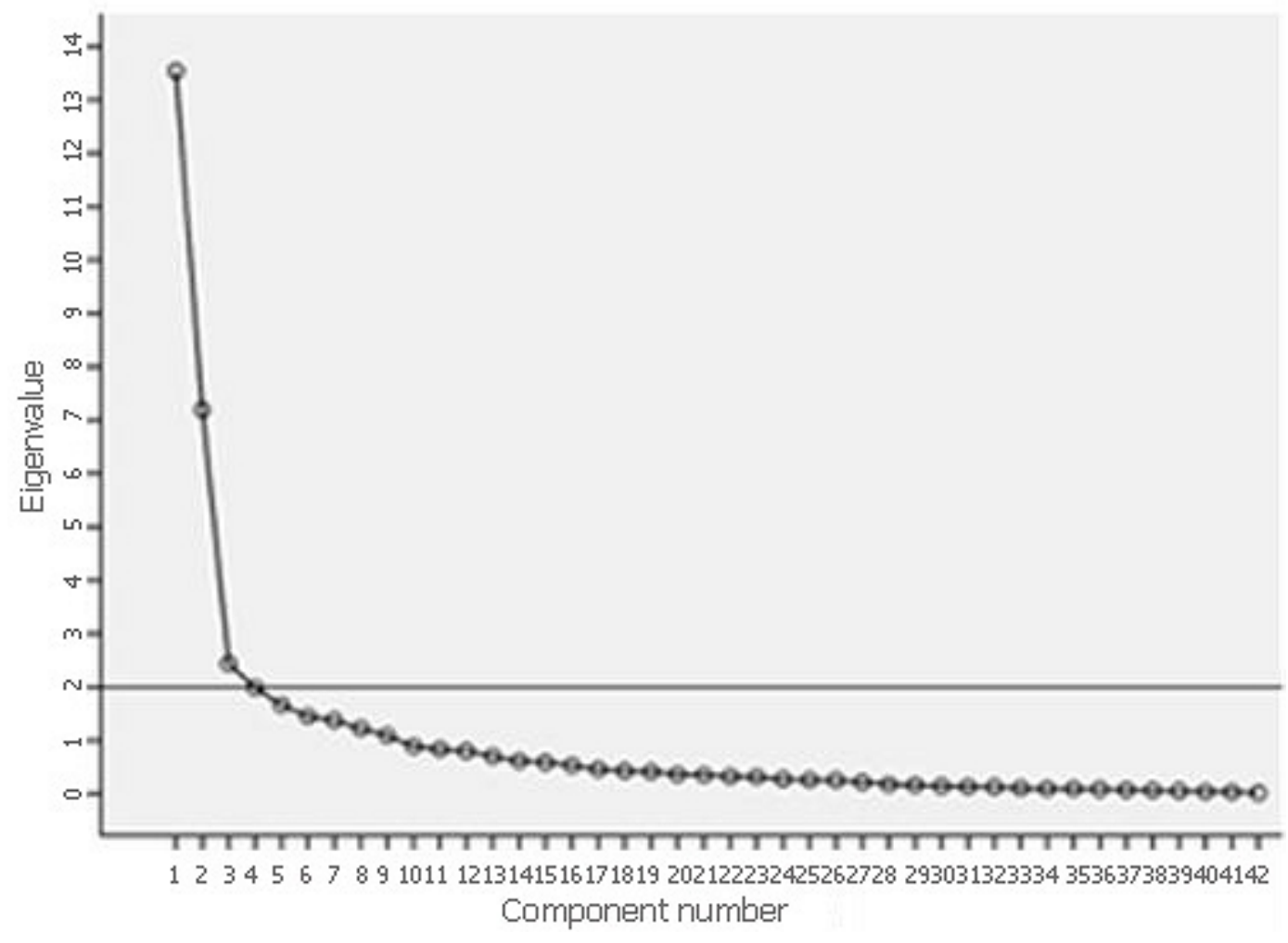

Figure 1. Scree Plot 
Table 3 shows the total variance explained. The total variance (measure of the indicators scattering) of a variable is a linear combination of factors [12]. The greater the percentage of variance caused by a factor is, the greater the weight of this factor. And the higher the cumulative percentage accumulated to the last factor is, the more successful is the factor solution. If this percentage is less than $50 \%$, then it is necessary to either reduce the number of variables or increase the number of factors. According to data in Table 3, the accumulated percentage of variance is quite acceptable and is about $60 \%$ (variance explained criteria).

Figure 1 shows a chart which is a diagram of eigenvalues and is called Scree Plot. The dot marks show the corresponding eigenvalues in the space of two coordinates. This type of chart is usually used to determine a sufficient number of factors before rotation. This is abided by the following rule: it is necessary to leave only those factors that correspond to the first dot marks on the diagram until the curve becomes flatter. According to the diagram (Figure 1), the number of factors is four.
Table 4. Component Transformation Matrix

\begin{tabular}{|c|c|c|c|c|}
\hline component & 1 & 2 & 3 & 4 \\
\hline 1 & -0.765 & 0.357 & 0.508 & 0.170 \\
\hline 2 & 0.598 & 0.681 & 0.334 & 0.260 \\
\hline 3 & 0.236 & -0.604 & 0.759 & 0.063 \\
\hline 4 & 0.043 & 0.210 & 0.233 & -0.949 \\
\hline
\end{tabular}

Once the number of factors has been determined, a rotation process takes place and it allows the results to be presented in a more convenient way and facilitates the interpretation of the factors. Then a principal components analysis (PCA) were carried out with the using Varimax rotation with Kaiser normalization. The results of the rotation are presented in Table 4.

A rotated component matrix (Table 5) is a result of multiplication the component transformation matrix $4 \times 4$ by the original factor loadings matrix, dimension $4 \times 42$. It is the one that carries the main information load in the whole process of factor analysis and is subject to meaningful interpretation of the results.

Table 5. Rotated Component Matrix

\begin{tabular}{|c|c|c|c|c|}
\hline & 1 & 2 & 3 & 4 \\
\hline Difficulties of understanding mathematics at university & 0.867 & & & \\
\hline Difficulties of studying the theorems proofs & 0.857 & & & \\
\hline Difficulty in taking colloquiums in mathematics & 0.857 & & & \\
\hline Level of basic school mathematics knowledge & -0.837 & & & \\
\hline Connection between school and university mathematics courses & -0.828 & & & \\
\hline The complexity of individual tasks & 0.823 & & & \\
\hline Content details of the university mathematics course & 0.805 & & & \\
\hline The complexity of mathematical symbols & 0.749 & & & \\
\hline The desire to get mathematical and professional competences & -0.732 & & & \\
\hline Interest in participating in subject competitions & -0.711 & & & \\
\hline Affordable understanding of mathematics at school & 0.707 & & & \\
\hline Difficulties in understanding lectures as a form of teaching process & 0.664 & & & \\
\hline The importance of revising a school math course with a university teacher & 0.663 & & & \\
\hline The level of self-organization in the educational process & -0.614 & & 0.529 & \\
\hline Difficulties in understanding seminars as a form of teaching process & 0.599 & & & \\
\hline Affordable understanding of mathematics teaching at university & 0.511 & & & \\
\hline The difference between school and university & 0.507 & & & \\
\hline Availability of information sources for independent work & & 0.713 & & \\
\hline The importance of having quality teaching materials & & 0.685 & & \\
\hline The importance of using smartphones in teaching & & 0.667 & & \\
\hline The importance of visual presentation of educational material & & 0.662 & & \\
\hline The importance of level differentiation, individual approach & & 0.653 & & \\
\hline The importance of test forms of control at university & & 0.646 & & \\
\hline The importance of using ICT as visual aids & & 0.634 & & \\
\hline The importance of having a distance course integrated into the discipline & & 0.622 & & \\
\hline The importance of using mathematical software & & 0.533 & & \\
\hline
\end{tabular}




\begin{tabular}{|c|c|c|c|}
\hline The importance of interactive teaching methods & 0.530 & & \\
\hline The importance of using distance learning technologies & 0.520 & & \\
\hline The importance of a unified assessment system at school and university & & 0.810 & \\
\hline The importance of understanding different assessment systems & & 0.808 & \\
\hline The importance of being able to translate points from one scale to another & & 0.804 & \\
\hline The importance of a mathematics teacher's personal example & & 0.597 & \\
\hline Wish to carry out pedagogical activity & & 0.569 & \\
\hline The importance of interesting intensive accessible teaching of mathematics & & 0.551 & 0.509 \\
\hline The importance of laboratory work using ICT & & 0.533 & \\
\hline The importance of applying knowledge to life situations & & & 0.666 \\
\hline The importance of content integration, interdisciplinary interconnection & & & 0.664 \\
\hline The importance and convenience of a 12 point scoring system & & & -0.523 \\
\hline
\end{tabular}

\subsection{Interpretation of Research Results}

The next stage of factor analysis is the interpretation of the calculation results. The calculated factor loadings from Table 5 were used.

Factor1. The components that have the highest absolute value of the correlation coefficient ( 0.9 to 0.8 ) are directly related to the content of the educational process. In addition, the first factor included components related to organizational forms of higher education. Considering such results, the first and most important factor was named as: "Providing Continuity through the Content of Education and the Form of the Educational Process Organization". This factor is the most important, since its contribution to the total variance is just over $25 \%$.

The interconnection between the components of the first factor can be found when considering the correlation matrix. The correlation matrix in the study has a dimension of $42 \times 42$ (it is too big to put it in this article).

The most important component of the first factor "the Difficulty of Understanding Mathematics at University" has a strong direct connection with such components as the "Difficulty in Studying the Proofs of Theorems", "The Complexity of Mathematical Symbols", "Content Details of the University Mathematics Course". This connection is clear and obvious. At the same time, there is a direct and strong connection between the difficulties in understanding teaching material and the difficulties in composing theoretical colloquiums, completing individual homework or independent work in mathematics. Also here an existing inverse connection with the level of self-organization in learning, since the better the student can plan and organize his/her learning activities, as well as control himself/herself, the more likely he/she will be able to execute intellectual efforts and overcome difficulties in perceiving the learning material, do well individual calculation tasks and prepare for colloquiums.

There is also a close direct link between the difficulty in understanding mathematics at university and the organizational forms of the educational process, such as lectures and seminars.

There is a close inverse connection between the difficulty in understanding mathematical disciplines and the interest and desire to participate in mathematical competitions and contests, since only that student who does not experience significant difficulties in learning and is interested in expanding and deepening his/her knowledge can be active in such activities.

Factor 2, which includes components that are directly related to different teaching tools and methods. This factor was named: "Providing Continuity through Traditional and Innovative Teaching Tools and Methods". The weight of this factor in the total variance is about $14 \%$.

The most important component in this factor is "Availability of Information Sources for Independent Work of Students". Consideration of the correlation matrix reveals direct connection with other components of the same factor and states that, apart from the availability of training materials, their quality, as well as methodological support with the use of ICT, providing clarity of presentation training material and individual approach is important. The connection between the availability of information sources and the importance of using level differentiation and individual approach to students by teachers were quite close. This was confirmed by an additional survey of students who in most cases answered that it was important for them to be able to consult teachers of mathematical disciplines to obtain guidance on the forming of a personal learning path.

Another significant component in the second factor is "The Importance of Using Smartphones in Teaching", which is understandable in today's information society, when most people, especially young people, cannot imagine their daily lives without a smartphone.

After analyzing the components that were included in the Factor 3, it got a name: "Providing Continuity through a Unified Assessment System and a Personal Example of a Teacher". The contribution of this factor to the total dispersion, same as the previous one, is about $14 \%$.

The obvious fact of the connection between "The 
Importance of a Unified Assessment System at School and University", "The Importance of Orientation in Different Assessment Systems", and "The Importance of Being Able to Translate Points from one Scale to Another" was confirmed by the results of the study. These components were combined into one block - the Evaluation System. Another components: "Importance of Personal Example of a Mathematical Disciplines Teacher", "Wish to Perform Pedagogical Activity", "Importance of Interesting Informative Teaching", "Level of Self-organization in Educational Process" were put in the second block "Personality of a Teacher". The calculated correlation coefficients show that there is a sufficiently strong direct connection between these components. It turned out that the personal example of a mathematics teacher, who provides interesting and informative teaching, influences the level of students' self-organization in learning and their wish for future pedagogical activity.

Factor 4 included the fewest components, but the combination of them is quite logical. Taking into account that the most important components in this factor are "The Importance of Applying Knowledge in Life Situations", "The Importance of Integrating Interdisciplinary Connections Content", "The Importance of Interesting, Informative and Easily Understood Teaching", which are highly correlated with each other (direct connection), it was named: "Providing Continuity through Integration and Applied Content Orientation". The contribution of this factor to the total variance is insignificant and is only $4 \%$.

\section{Conclusions and Future Research}

The conducted research allowed us to define the factors that influence the process of providing the continuity of mathematics teaching in the system "School-Pedagogical University". These factors are:

1. Providing Continuity through the Content of Education and the Forms of Educational Process Organization

2. Providing Continuity through Traditional and Innovative Teaching Tools and Methods.

3. Providing Continuity through a Unified Assessment System and a Personal Example of a Teacher.

4. Providing Continuity through Integration and Applied Content Focus.

The next stage of this study is planning and construction of an effective methodical system for providing the continuity of teaching mathematics in the system "School-Pedagogical University", which takes into account all the distinguished factors. Methodical systems of education usually contain such components as goals, content, forms, methods, learning tools. The results of the study indicate that the methodical system should include learning outcomes, interdisciplinary connections and interpersonal connections. Components in this methodical system should be combine based on factor relationships identified by factor analysis. For example, content and forms; teaching methods and learning tools.

Factor analysis made it possible to establish that during the implementation of this methodical system, it is necessary to:

- $\quad$ pay special attention to the content of the educational material at school, considering the need to continue studying mathematics at university;

- prepare students at school for special forms of conducting classes at the university, in particular lectures and seminars, colloquiums, as well as to prepare them for the need to perform a large amount of independent work;

- $\quad$ step by step introduce classical mathematical symbolism at school and teach students to prove the simplest mathematical statements;

- methods of teaching mathematics and learning tools used at school and university should be similar. For example, testing is often used at schools, but much less at university; distance learning is used at university, but almost absent at school, etc.;

- assessment systems at school and university are different (12 points scoring system at school and 100 points at university), so this creates difficulties for adequate self-assessment;

- both at school and at university it is necessary to pay attention to the applied content orientation of mathematics, its interdisciplinary connections.

Such results allow us to plan further research and to design and implement a coherent methodical system for providing the continuity of mathematics education when students are transferred from school to university.

\section{REFERENCES}

[1] Ananiev, B. About Continuity in Training, Soviet Pedagogy, No.2, 23-35, 2015.

[2] Batarshev, A. The Pedagogical System of Continuity of Education at School and Vocational School, Russian Academy of Education, Saint Petersburg, 1990.

[3] Bosovsky, M. Continuity in the Study of Limit Theory at School and University, Cherkasy, 2010.

[4] Buyul, A. and Zefel, P. SPSS: Art of Information Processing. Analysis of Statistical Data and Restoration of Hidden Patterns, DiaSoftUP LLC, Saint Petersburg, 2005.

[5] Carter, K. and McNeill, J. Coping with the Darkness of Transition: Students as the Leading Lights of Guidance at Induction to Higher Education, British Journal of Guidance and Counselling, 26(3), 399-415, 1998.

[6] Didovik, M. Continuity of Physical and Mathematical Preparation in Lyceums and Higher Educational Institutions III - IV Accreditation Levels, Vinnytsia, 2007. 
[7] Gnyezdilova, K. Formation of Readiness of the Future Mathematics Teacher to Provide Continuity of Education in Secondary School and Higher Education Institution, Kirovohrad, 2006.

[8] Huon, G. and Sankey, M. The Transition to University: Understanding Differences in Success, paper presented at the 6th Pacific Rim First Year in Higher Education Conference: Changing Agendas, University of Canterbury, Christchurch, New Zealand, 8-10 July, 2002.

[9] Keup, J. and Barefoot, B. Learning How to Be a Successful Student: Exploring the Impact of First-year Seminars on Student Outcomes, Journal of the First-Year Experience and Students in Transition, 17(1), 11-47, 2005.

[10] Klimchuk, V. Factor Analysis: Use in Psychological Research, Practical Psychology and Social Work, No.8, 43-48, 2006.

[11] Komarova, E. Continuity in Teaching Arithmetic and Algebra as a Means of Increasing the Effectiveness of Mathematical Training of Students in Rural Schools, Moskow, 2006.

[12] Lebedeva, I. About Specificity of Application of Factor Analysis in Pedagogical Research, Education and Science, No.2, 10-25, 2003.

[13] Mikhailov, P. Continuity in Educational Work at the Preparatory Department and First Courses as a Didactic Condition for Increasing the Effectiveness of Training, Chelyabinsk, 1982.

[14] Mishareva, K., Rudenko, V. and Shepetov, A. Propaedeutics of Mathematical Education, Prosveschenie, Moskow, 1973.

[15] Pascarella, E. and Terenzini, P. How College Affects Students (Vol 2): A Third Decade of Research, San Francisco, Jossey-Bass, 2005.

[16] Peel, M. Nobody Cares: the Challenge of Isolation in School to University Transition, Journal of Institutional Research, 9(1), 122-34, 2000.

[17] Pitkethly, A. and Prosser, M. The First Year Experience Project: Model for University-Wide Change, Higher Education Research and Development, 20(2), 185-198, 2001.

[18] Pyshkalo, A. Continuity in Teaching Mathematics: A manual for teachers. Digest of Articles, Prosveschenie, Moskow, 1978.

[19] Smantser, A. Theory and Practice of the Implementation of Continuity in the Teaching of Pupils and Students, BSU, Minsk, 2013.

[20] Stonda, O. Didactic Conditions for Providing Continuity in the Education of Students of Pedagogical Universities, Collection of Scientific Works "Pedagogy and Psychology", No.50, 40-47.

[21] Westlake, C. Predicting Student Withdrawal: Examining the Reasons through a Preliminary Literature Review, Newport CELT Journal, 1, 29-33, 2008.

[22] Yorke, M. and Thomas, L. Improving the Retention of Students from Lower Socio-economic Groups, Journal of Higher Education Policy and Management, 25(1), 63-74, 2003. 